\title{
The Role of Etymology in the Teaching of Idioms Related to Colours in an $\mathbf{L} 2$
}

\author{
Elena María García Moreno \\ Facultad de Traducción e Interpretación \\ Universidad de Granada
}

Received: 4 March 2010 / Accepted: 12 September 2010

ISSN: $1697-7467$

\begin{abstract}
Teaching figurative language, in general, and idioms, in particular, is one of the most controversial and difficult areas in L2 teaching, as it seems to be a big challenge from a cultural point of view and, subsequently, from a pedagogical one. With regard to idioms related to colours, these expressions differ highly depending on whether their origin is Spanish or Anglo-Saxon. Examples ranging from colours such as white, black and red to blue, yellow and green will be the axis of our study.

Through etymology we will be able to ascertain the root of these fixed expressions and provide some tips regarding their teachability/learnability. The use of etymology as a didactic tool, combined with illustrations, games, and dynamic exercises, will help students to understand these idioms, which are the reflection of a culture.
\end{abstract}

Keywords: figurative language, idioms related to colours, methodology, etymology.

\section{El rol de la etimología en la enseñanza de los modismos relacionados con} los colores en una $\mathbf{L} 2$

RESUMEN: La enseñanza del lenguaje figurado, en general, y de los modismos, en particular, es uno de los temas más difíciles y polémicos en la enseñanza de L2, ya que se considera un obstáculo desde un punto de vista cultural y, por tanto, pedagógico. En cuanto a los modismos que incluyen colores en su articulación, estas expresiones difieren sustancialmente dependiendo de los orígenes que se arraigan en la cultura española o anglosajona. A este respecto, el eje principal de nuestro estudio serán ejemplos que oscilan desde algunos de los colores, como el blanco, negro y rojo hasta el azul, amarillo y verde.

A través de la etimología podremos establecer lo esencial de estos modismos y ofrecer alguna sugerencia respecto a la enseñanza y el aprendizaje de los mismos. El uso de la etimología como herramienta didáctica en conjunto con ilustraciones, juegos, y ejercicios dinámicos ayudará a los estudiantes a entender estos modismos, reflejo de una cultura.

Palabras clave: lenguaje figurado, modismos relacionados con los colores, metodología, etimología.

\section{INTRODUCTION}

There is a lot of literature that deals with figurative language and the value of all the phenomena embraced under this label within the L2 teaching. Defining and 
understanding what the object of our study is, and what it entails from a macro to a micro-level, is the essential first step before further analysis.

In an attempt to define figurative language, it is crucial to remind ourselves that language is a dynamic process which is in constant flux. In fact, for human beings communicating is never merely a question of conveying information. Language has a multi-functional dimension which enables us to talk for the sake of talking, to say the opposite of what we mean and even to produce misunderstandings. All these nuances make communication a dynamic process in which participants take turns, negotiate and eventually transmit information. The importance of language teaching, therefore, relies on this.

By the same token, figurative language is part and parcel of what is broadly speaking considered to be general English. For this reason, it should be learnt and taught, despite the high degree of difficulty and the complications this may involve. In a more detailed approach to the context, and following Israel's words, we could start by saying that the «literal meaning of a word is the meaning inherent in its letters: it is the 'plain' meaning of a text, opposed to 'figurative' senses requiring a richer mode of interpretation» (2002:424) or what is the same, and as others scholars assert, literal language is conventionally called «context-free, semantic meaning» (Gibbs 2002:475). This is defined by the Oxford English Dictionary as one that «expresses one thing in terms normally denoting another with which it may be regarded as analogous». In this sense, it is clear that of all the kinds of non literal expressions (metaphors, similes, symbols, ironies, hyperboles, allegories...) idioms are the most frequently encountered in discourse.

If we focus our study we talk then about idioms. Idioms have a complex nature that many scholars have tried to clarify. Despite the general definition given by the Oxford English Dictionary as «a form of expression, grammatical construction, phrase, peculiar to a language; a peculiarity of phraseology approved by the usage of a language, and often having a signification other than its grammatical or logical one», authors such as Rosamund Moon take a further step and define idioms as «lexical anomalies, frozen or near-frozen expressions whose lexical composition belies their semantic meaning and that must be described and understood in situ, based on corpus evidence» (1996:245). However, if we translate that into plain English, it could be said that the most important consideration for idiomacity lies in the fact that the meaning of the whole «cannot be predicted from the meanings of the constituent parts» (Kövesces and Szabó 1996:326).

What they all seem to agree is that the following are inherent features of an idiom:

1) Metaphority: idioms are not dead, there exists a relationship between the literal and figurative meaning at least in the etymology of the expression (Cronk and Schweigert 1992, Nippold and Rudzinski, 1993).

2) Analysability/non-Compositionality: «the meaning of an idiom is not predictable just from the meaning of the individual words that make it up» (Lakoff 1987:448).

3) Fixedness of form or what is the same, frozenness or invariance in appearance. Other authors prefer to call it «stability» (Gläser 1988:266).

4) Multi-word expressions. An idiom consists of more than just one word. 
As far as its classification is concerned, it is vital to highlight the difference between transparent idioms, whose syntactic structure is equal to its non-idiomatic meaning such as to give the green light and opaque idioms, whose structure was disjointed from that of its idiomatic meaning such as be home and dry, since as it will be seen further on, this distinction will have an influence on methodology, in the manner of teaching them.

But apart from being the definitions already given, to all these scholarly approaches, what is really clear about the mingled nature of idioms is that idiomatic expressions are, after all, the patrimony of a culture and tradition, they epitomize centuries of life in a particular sociolinguistic context and geographical setting and are the heart and soul of a linguistic community and part and parcel of our lives.

\section{Methodological enQuiries: why AND how?}

Once we have understood the nature and implications of figurative language in general and of the idiom in particular, a question should be raised: Why is it so crucial teaching idioms? The answer is grounded on several main aspects.

First of all, idioms are the grease that makes language flow and thus, figurative competence in foreign language learning contributes to an overall level of communicative competence. Idiomatic expressions give language a peculiar flavour and give it variety, character and colour. In similar vein, they help language learners understand English culture, penetrate into customs and lifestyles of English people, and facilitate a deeper insight into English history. As it can be confirmed when we travel abroad, native speakers use idioms all the time and most of the time students get discouraged and feel distressed if they cannot understand them. The sheer number of idioms and their high frequency in discourse make them a noteworthy aspect of vocabulary acquisition and language learning in general.

Secondly, idioms' teachability/learnability should be paid special attention, since according to studies in the cognitive linguistic arena, it has been shown the importance of the role played by the memory when learning these fixed expressions and, hence, it is a methodological aspect to bear in mind.

Finally, not all idioms are comparable to expressions in other languages as many of them come from older phrases which have changed over the years; they are in a constant flux. In order to ascertain the roots which underline their essence we have to resort to cultural and even anthropological factors, as well as to a diachronic view of the language. Here relies the importance of etymology when teaching idioms as we will see afterwards.

At this stage, it would be appropriate to ask: how do students process idioms? There is much literature about this. As it is obvious, learning idioms presents a host of difficulties to English learners, primarily because they do not know the culture and history behind English idioms and they often use idioms inappropriately in a situation. According to some authors (Cronk \& Schweigert, 1992) they do it by the inactive mode, or in other words, students process the figurative meaning and this only becomes active 
when the literal interpretation is inappropriate to the context. To put it simply, only once students have realised that the literal meaning is not suitable for the context, their cognitive structures can embark upon seeking for a figurative meaning that has the communicative solution. Deriving from this, other authors underline the importance of context for comprehending the idiomatic expressions (Cacciari \& Levorato, 1989).

In addition, authors such as Irujo (1986) carried out an academic work to verify whether advanced learners of English use knowledge of their first language to comprehend and produce second language idioms. The results were that interchangeable idioms were easier to appreciate and produce, and that unconnected idioms were harder to apprehend. In the light of this, the existence of a two-fold structure cannot be denied in cognitive linguistics where there are two types of information: the notional information (the capital meaning of the word typifying the concept) and the associative information (individual experience and perception of reality), this latter being determined by the specificity of the culture itself. This is another reason that unveils how important is to enquire into culturally marked associations. But in our attempt as teachers of EFL, what problems do we face when teaching idioms?

Idioms pose particular problems in language learning and teaching as we pointed out at the beginning of this paper. The above-mentioned versatility in the usage and meaning of idioms, in addition to their metaphority, makes them a real challenge to language users, in particular to second or foreign language learners. Opinions on how and what to teach and learn about idioms have been manifold according to which idioms characteristics have been highlighted. Similarly, studies have concentrated also on whether foreign language learners ought to be taught easily analysable, transparent idioms, or whether idioms whose roots were more difficult to detect were more worth teaching (opaque idioms).

For our purpose, despite the fact that transparent idioms are more easily recognisable by students than opaque ones, it is our goal to highlight the importance of the etymology in understanding the latter, where the motivation behind the figurative meaning is impossible unless you know the origins. Both types of idioms should be taught and learnt in the same way and to the same degree. However, it is true that transparent idioms are more easily recognised and learnt in early years and opaque ones by advanced students.

Moreover, idioms related to colours echo specific beliefs held by a particular culture. If we single out the cultural components of idioms' meanings, they reflect the cultural information that the colour concepts contain; they are connected with traditions, customs, beliefs and events belonging to a culture. It is precisely this «culture-bound nature that makes them unmanageable for learners who do not belong to the same linguistic community and who cannot instinctively-as native speakers do- recognize a clear semantic, pragmatic and syntactic pattern» (Irujo, 1986). What can therefore not be naturally and instinctively recognized must therefore be made recognizable through analysis and reflection: learners must be made aware that the meaning, use and structure of idioms can, like other elements of the English language, also be controlled.

It is crucial to assume that the meaning of many idioms are, in part, motivated by the student's conceptual knowledge of the concepts to which idioms relate to, and that students will acquire more easily the idioms that are syntactically frozen and those whose literal meaning is close to their figurative one, that is, that are transparent. In a similar fashion, throughout their childhood children are exposed to figuration by means of cartoons, 
songs, stories, adverts, teacher talk, and it seems likely that they learn to benefit from this exposure at an early stage. By the same token, context is essential and it is configured as the necessary tool that provides the semantic information necessary to assign coherence to the text and to extract the figurative sense, going beyond the words and attain the global sense of the text.

\section{The Rainbow of language: an etymological apProach}

\subsection{Previous considerations}

It is widely-known that colours evoke a meaning. Languages are full of colour word expressions which refer to ideas that lie beyond the literal extensions of colour denotation: green with envy, to have the blues, to see red. However, do these conventional linguistic expressions actually put into words the meanings that dwell in their etymological heart? Although it is possible to discover the origins of colour word expressions and the connotative meanings they stem from, discovering what semantic values the colour words actually render within these phrases in natural discourse is not such a straightforward matter. Could we say, for instance, that the use of the phrase 'out of the blue' necessarily evokes the relation between blue and sky? If someone is said to be 'caught red-handed', is blood actually involved?

When knowing the etymology inside out, it is pivotal to carry out a wide-ranging overview of colour meaning from antiquity to the present day, spanning a wide scope of disciplines. Ranging from historical-philosophical, aesthetic, anthropological, psychological to popular viewpoints, each sheds a different light on the topic of meaning in relation to colour idioms.

It is again important to stress the point that the vast majority of language users are ignorant of the etymology of the words and phrases, and for this reason, linguists must be wary of an over-reliance on factual, though often trivial, etymological information when trying to shed light on pragmatic meaning.

Colours have been relevant since the earliest times. They were assigned meanings over two thousand years ago and they have been modified very little to the extent that they now generally go unquestioned. It is essential to mention some historical references at this point. One of them is the Hippocratic School of medicine. The Hippocratic School of medicine's division of personalities into the four humours -sanguine, phlegmatic, choleric and melancholic -has a natural progression into the field of colour symbolism. The fiery sanguine character corresponds to blood and thus has a natural analogy with the colour red; choleric (or bilious) and melancholic characters are caused by excessive quantities of one or other of the two colours of bile - yellow and black respectively - and these again are assumed to be the actual colours of bile. White corresponds to the slow, phlegmatic character as it is the colour of healthy phlegm.

Another reference is the Platonic system, which assigns blue to the air, green to water, yellow to earth, and red to fire. These correspond to our modern perception of the colours, especially if we remember that the context of their application is the Mediterranean region: the sky is blue, the water is blue-green, yellow (ochre) is the colour of the soil, and flames tend towards the orange-red end of the colour spectrum. 
The semantic structure of some colours has quite similar components both in the Spanish and English languages. As far as the national differences in the semantic structure of a colour are concerned, these are caused by cultural, political or purely linguistic factors. So colours are able to evoke certain kind of material, abstract, sensory and emotional associations. However, the nature of colour is more troublesome than just a wave-length. It comprises emotional and symbolic components as well as purely visual ones. But, why? Let us examine some examples of each colour.

\subsection{Black and white}

Black has been considered a primary colour in the past. Together with white it contains all the colours of the spectrum in combination. As black is the colour of darkness, it has been symbolically related to evil, and by extension, with everything which is impure and has an affinity with the dark. According to Plato (360 B.C) evil, ugliness, wilfulness and black are connected. In the medieval period black and white were symbols of evil and good and the religious notions of sin and purity respectively.

It could be said then that this colour is used for referring to phrases connected with sad or unpleasant things, dark purposes, and for something harmful. Let us study some expressions in more detail:

- To be the black sheep is the same as in Spanish ser la oveja negra. This description refers to someone who does not fit in with their family's ideals. This expression goes back as far as a 1550. Shepherds of those times considered that a black sheep bothered the rest of the flock. Furthermore black wool could not be dyed to different colours and was therefore less valuable than white wool.

- To be in someone's black books or to be on the black list is the same as in Spanish estar en la lista negra. Black books were a commonplace in medieval times as they were records of law and customs of the times. At about the same time merchants began to keep records of bad debts and black books were coined for persons who had gone bankrupt. Later still Oxford and Cambridge Universities kept black books and lists of people guilty of misconduct that could not then advance in their careers.

- In both cultures we also detect this symbolic negative connotation in idioms such as black market: mercado negro, black humour: humor negro and black magic: magia negra which does harm and, like all things related with black, is related to evil, misery and destitution. To give someone a black eye means to hit somebody but in Spanish we find this expression has the colour purple: ponerle a alguien un ojo morado, referring thus to the colour of the bruise resulting from hitting. You also are giving someone a black look if you are frowning or scowling at someone.

English also demonstrates in expressions such as not as black as s/he painted now an attempt is made to salvage somebody's character. In the expression the pot calling the kettle black the accuser is told to consider his/her own actions before criticising those of other people. The origins of this phrase date back to Cervantes' Don Quixote. 
Black also appears combined with other colours. As we have said, it appears with white: Black and white signifies a very clear choice that causes no confusion. By the same token, in black and white denotes the written or printed form. This expression is based on the idea of black printing or writing on white paper. In this sense there is an expression in Spanish, poner algo en negro sobre blanco, that is used when you talk with clarity. It also appears combined with red. For instance, in the financial sphere we find that credits are traditionally noted in black ink and debits are noted in red, originally to differentiate and highlight the two sides of the account. The expressions (go) into the red: estar en numeros rojos and (come) out of the red/ move into the black date back to 1928 and is a standard practice for accounting. The positive numbers are recorded in black ink and the negative numbers in red. Following a logical reasoning, to be in the black is to be making money. In medieval times the church, being the only centre of literacy and learning in the west, maintained meticulous accounting records. Ink at that time was rare and expensive, so, when monasteries and churches had little money and they could not afford ink, domesticated animals were bled to provide a substitute. As a result, poor financial records were usually written in the red.

\subsection{White}

As we have said, the white/black, good/evil distinction was also recognised by the ancient Greeks: Plato writes that «white is a colour suitable to the Gods» (360 B.C a). Apart from the above-mentioned here we have some other examples:

- White with pain and pale with fear are phrases which reflect the draining of blood from the body when we are injured or afraid. In Spanish we also find quedarse pálido referring to this colour of the body and face.

- A white elephant would be given to someone considered to be an enemy. White elephants were regarded as holy in ancient times in Asian countries. To keep a white elephant was very expensive, since you had to give the elephant special food, and to provide access for people who wanted to come and worship it. If a Thai King became dissatisfied with a subordinate, he would give him a white elephant. The gift would, in most cases, ruin the recipient.

- A white lie, in Spanish, una mentira piadosa, is a lie which is told not to upset someone.

- You can also whitewash something which means to cover the truth.

- As white as snow, in Spanish tan blanco como la nieve, limpio como una patena or limpio como los chorros del oro. What better to symbolise whiteness and purity than snow and cleanliness?

- Whiter than white: the expression refers to absolute moral purity but it may also be used ironically. In similar fashion, we find in Spanish estar sin blanca. The blanca was a coin that was used during the kingdom of Pedro the First. This coin lost importance and quality. For that reason, estar sin blanca is associated to someone who does not have the essential necessities to survive. There are other expressions such as de punta en blanco. This expression has its origins when the knights used to carry all their weapons prepared for the fight. As these 
weapons were made of steel, they had a shining white colour resulting from the sunlight.

\subsection{Red}

As mentioned above, the ancient Greeks also based their colour theories on red. Democritus associated red with heat and Plato assigned red to the element fire. In the Hippocratic school of medicine, red was associated with the sanguine humour and with blood. It is also «an expression of feverish, belligerent passion» as well as passionate physical love. Red is linked to Mars and also to soldiers and revolutionaries. Red is a symbol of light and radiance, of fire, and perhaps of Hell for this reason. It also represents the blood of life and the blood which has been spilled in death, as well as war, passion, rage, and revolution.

- To be as red as a beetroot indicates deep embarrassment. Red as a lobster, on the other hand, is used to describe sunburn.

- Red with anger or to see red indicates the rush of blood to the face associated with anger.

- A red letter day is a holiday, a cause for celebration. Calendars typically have holidays marked in red ink whereas other days are in black.

- To be caught red-handed. In this idiom, the colour red originally referred to blood. As a meaningful unit in current English, this expression is not used to talk about violent crime (murder in particular), which would cause red hands, but rather about theft and illegal dealing in drugs and arms, which are not generally bloody activities. To «catch red-handed' is not selected for its image but for its meaning.

- To be a red, ser un rojo, has to do with politics as red has always been associated with communism and left wing politics.

- Ponerse colorado/to go red refers to the colour of the face when you blush.

- To roll out the red carpet. This expression has an Indian origin. The red colour served to identify the emperor's tent, and luxurious textiles, not only provided the comforts of home but also symbolically reminded envoys and visitors of the power and the wealth of their rulers.

\subsection{Blue}

In early sources, blue refers to the air, the sky and heaven, and thus by extension it also represents divinity, faith, spirituality, constancy and loyalty. Until the Renaissance, darker blues were symbolically related to black, and darkness, with all the symbolism resulting from this. The Blaue Reiter made blue the masculine colour just as yellow was for them the feminine. Blue was not only masculine, but also «sharp and spiritual and cool».

- Unexpected events can be said to come like a bolt from the blue or out of the blue, and are thus compared to a lightning bolt appearing in a clear blue sky - 
not a dark, stormy one where it might be expected. Infrequent events are said to occur once in a blue moon. The blue moon is not in fact a metaphor, but a real phenomenon whereby the moon takes on a blue tinge. As the expression suggests, this occurs very infrequently. When two full moons occur within 28 days we call that period a blue moon. Something which happens once in a blue moon therefore, happens very seldom.

- Extreme cold can result in frost bite where the skin turns white with blotches of blue, so we talk of being blue with cold. Just «being blue» or «having the blues» is feeling depressed.

- To have blue blood in one's veins is a literal translation of the Spanish sangre $a z u l$, attributed to some of the oldest and proudest families of Castile, who claimed never to have intermarried with Moors, Jews, or other races. The expression probably originated in the blueness of the veins of people of fair complexion as compared with those of dark skin. That was certainly the understanding in the $19^{\text {th }}$ century, and there seems little reason to doubt it.

- However, water is not always clear and calm, but often turbulent, unpredictable and full of unknown danger. Thus to be caught between the devil and the deep blue sea is to be stuck in a no-win situation, where either course of action is as risky and undesirable as the other. Set against that there's the explanation that this is from the usual meaning of the devil. If we are talking about the devil then the origin is logical - «the devil is bad»; «falling in the deep sea is bad», so to be caught between the two would to be in difficulty.

- A blue joke/book/film. In the 1980's pornographic content in Video Cassettes was sealed using blue tape, and hence the name.

\subsection{Green}

Green was considered by Aristotle to be one of the three primary colours between black and white, and one of the three colours of the rainbow, alongside red and purple. In medieval times, green was the colour of faith, and also the colour of plant life and hence newness, youth and vigour. It could also indicate promiscuity, as this is vigour in excess.

The Blaue Reiter group, treated yellow as a primary colour and excluded green: green is the colour of vegetation and nature, «fruitfulness and contentment, tranquillity and hope» as well as «the fusion and interpretation of knowledge and faith». In the same way, green has very little in the way of symbolic meaning, being used primarily to refer by metonymy to vegetation, and by extension to life, growth and fertility.

- Become green with envy means to envy someone extremely.

- A green horse is a person who is youthful and inexperienced, just like the green branch of a tree is young and untried by storms.

- Green-eyed-monster means to be jealous. Shakespeare wrote about the green monster of jealousy in his play Othello and today we still speak of the little green monster or of being green with envy. If you believe that the grass is greener on the other side, you want something that's just out of your reach, just like cattle which always want to eat in the field next to where they are left by the farmer. 
- To get the green light means that you can do something. It is green like the traffic light so you are given permission.

- To have green fingers refers to being very good at gardening.

- In Spanish we find expressions such as viejo verde/chiste verde. The origins of this expression is the following: the Latin word «viridis» was applied to old people who had a young spirit. Virgilio was the first to use this viejo/verde combination referring to Caronte (Eneida, 304). In Spanish the adjective verde had the Latin meaning till the $17^{\text {th }}$ century. A viejo verde was just simply an old man with young appearance. But from that moment onwards, the expression had lascivious connotations. As love and sex were associated more with young people, a viejo verde became an old sexually active man.

- A buenas horas, mangas verdes is a Spanish expression that has its origins in the Court of the Santa Hermandad which used to judge and punish crimes. At first, the soldiers of this Court (whose uniforms had green sleeves (mangas verdes)) used to arrive on time, but they increasingly became more unpunctual, so the expression was a buenas horas, mangas verde, that means, you are arriving too late.

- Poner verde a alguien in Spanish is to criticize as it refers to the colour of your face when you are being criticized.

\subsection{Yellow}

Plato ascribed yellow to the earth. Yellow, in Hippocratic medicine, corresponds to the choleric personality, though it is opportune to point out that here too it was almost certainly a greenish-yellow colour. Yellow on the other hand, was the colour of jealousy, as it still is in most of Europe.

Yellow is the colour of light, and by extension (in some sources) of intelligence and knowledge. It is the colour of earth and of fire, of jealousy and cowardice. Yellow can also be a symbol of gold, though this is more favoured by modern sources than by older ones.

- Cowardly people are said to have a yellow streak. In the past, men who refused to fight in wars were given the white feather from a chicken, a bird which symbolized cowardice. In English it is associated with cowardice, again deriving from the colour of bile.

- Yellow press, prensa amarilla. The obsolete 'yellow press' is equivalent to the

- 'red-top' tabloids of the present. It, like them, owes its name to the colour of the newspaper title on the front page, and occupied itself with scandal and shockhorror tales. By extension, the term came to mean scandalous and scurrilous journalism.

- The goose that lays the golden eggs, matar la gallina de los huevos de oro. Good or unique opportunities are called golden opportunities, gold being a precious metal.

- No es oro todo lo que reluce means not everything is good or precious. 
The Role Etymology in the Teaching of Idioms Related...

\section{Methodology}

Because of their high frequency in discourse, it is clear then that idioms require special attention in language programmes and syllabuses and should not be relegated to a position of secondary importance in the curriculum. In this respect, the majority of courses for foreign learners of English include idiomatic expressions at the end of didactic units and by means of exercises that fail to disclose their complex nature and strong connections with every day language. Consequently, learners generally come to regard idioms as awkward and unhandy lexical items unrelated to real English.

As far as methodology is concerned, I think that there are three main goals that should be followed by teachers and students when dealing with idioms:

1. To control their meaning. The first thing learners of English should be aware of is that idioms are strongly tied to the culture and history of the people that generate them, «their top structures always tell a story that justifies their bottom meanings» (Pinnavia 2002:55). They will then realize that idiomatic expressions unfold stories that suddenly give a sense to their real meanings. They have to be aware that the source and the lexical area to which an idiom belongs can illumine its non-literal meaning. This can instil in the learner as analytical meaningdeciphering approach when having to confront other unknown idioms. Another way, in which the meaning of idioms can be controlled, is through a contrastive analysis with the learners' mother-tongue.

2. To control their structure. For the sake of simplicity, learners are normally told that idioms are inflexible and cannot be transformed in any way. This is a myth that should be exploded; learners can be shown that while some idioms cannot admit any type of variation (red herring), others can accept both those of the lexical and the grammatical kind. So, it is important to highlight the versatility of idiom.

3. To control their function. Idioms are readily transformed in order to achieve certain stylistic effects. Idioms are themselves texts with a very strong communication force. For that reason, they are predominant in text types such as adverts, newspaper articles, where the presumed interactivity between the writer/speaker and reader/listener is high.

But, how do we bring these aspects into our classroom reality? In a student-centred methodology, there are a large number of different activities we can resort to for our teaching purposes. In L2 traditional activities designed to promote the comprehension of idioms include matching, guessing and gap filling, replacing and rewriting to encourage idiom production.

The suggested activities to exploit this idea in the classroom varies from presenting students with texts or lists of expressions where they have to identify the items that are used metaphorically and the conceptual metaphor behind them. On the one hand, these activities offer a systematic way of teaching figurative language which, on the one hand, clarifies certain mental and linguistic patterns. We can also relate them to human ways of categorisation, facilitating their incorporation to mental schemata. In fact, dividing idioms into thematic categories may ease the task of teaching idioms. 
However, the most common exercises used in the classes contain the following: drawing idioms (in which the contrast between literal and figurative meanings is shown), dramatizing idioms using charades (in order to compare in a humorous way literal and figurative meanings of idioms), students can act out the literal meaning of an expression and the class can guess the figurative meaning. These exercises may generate mental images of idioms and facilitate comprehension (as pointed out the study conducted by Cacciari \& Glucksbert (1995). Another idea, widely employed, is the retelling exercise: the teacher tells a story including several idioms and the students have to retell it or write it down trying to use as many of the expressions as they can. If you want to approach idioms in a different and much fresher way, write a list of them on the board and start the narrative by using one of the idioms. Each student contributes one sentence containing a new expression. As they personalise their piece of writing students will retain more easily the idioms they have used. Idioms can also be explored through read-alouds and student-centred activities that are presented in the classroom and that are designed to further develop their understanding of figurative language.

However, resorting to etymology to unveil the idioms' origins may be a quite rewarding and powerful pedagogic tool as explained along this paper. Either by explaining the origin beforehand or after the exercise, both are useful ways of retaining the underlying meaning of the idiomatic expression. Students will only gain a deeper insight into the expression when they come to grips with the origins of that expression. Hence, pictures, retelling and drama exercises, just to mention a few, should be employed to work on these origins.

Apart from that, and as the Common European Framework points out, it is of highly importance for our students to be exposed to different text types and genres. For the purpose of gaining a deeper insight into the lexical features of different types, we can resort to the analysis of idioms, discussing idioms from newspapers comic strips, cartoons, from TV shows, among others. The teacher can also omit the idiom from a paragraph and have students complete the passage with a phrase that fits the context, give the omitted idiom, so that students will see how they have inferred the idioms' meaning from the context (Irujo, 1986). Another interesting activity is to give students newspapers and magazines and in groups of three: students flick through the pages and underline five idioms that they may find interesting (either in headlines or in other parts). Then, they discuss on their meaning, register, context and other outstanding features and share with the rest of the class.

We should not forget the role that the ICT (Information and Communication Technologies) play within the L2 classes. Internet is a comprehensive realm full of websites where students can practice and learn idioms of different types (more slang idioms, per topic, etc.). The teacher must select some useful links and provide students with this tool to reinforce and enhance their autonomous learning. Some of the exercises related to idioms that can be found are highly motivating and innovative. In some cases, students do just a fill in the gaps but reaching a score, in a more interactive way. Within the classroom, we can also resort to the new technologies, carefully selecting the material and procedure. For instance, we can play any video from YouTube where common daily-life based idioms appear. Firstly, students must draw their attention to the video and write down all the idioms they hear to activate recognition. Then, in pairs, they compare answers and try to guess the meaning from the context. 
Afterwards, the video is played again with subtitles and students check their answers. In the activation phase, students rehearse idioms through dialogues, as it is of paramount importance to contextualise and to produce them. Similarly, song videos can be employed. Students are given the lyrics and some gaps (the gaps are part of an idiom). Students have to predict information, and then they listen to the song and check. This offers a great multisensorial input, as we not only rely on visual input but on the oral one.

To finish with, the use of PowerPoints and of pictures (suitable for visual learners, who associate images to words) is great to portray examples in dialogues on how to use them. Students practice dialogues, making use of idioms to fulfil the required functions, they memorize them improving in this way their communicative competence.

\section{Conclusion}

All in all, we could highlight three main aspects. Firstly, figurative language teaching in general, idioms in particular is very complex and, therefore, poses many problems not only from a pedagogical point of view, but from a cultural one. It is clear, however, that these fixed expressions, due to their high frequency in discourse, should be included in the curriculum and not be relegated to a secondary position

Secondly, it is crucial to teach these idioms as part of a culture, reflection of beliefs of a community. Studying the etymology is essential for that purpose, since these expressions were coined in a specific moment and because of cultural reasons that cannot be found out by merely analysing the constituent parts of the expression itself. As it has been seen, each colour has a specific semantic content, so, if we explain and transfer this semantic content to our students, they will be able to associate them with the figurative meaning, and thus, they will be able to infer the idioms' meanings from the context. The national differences, thus, in the semantic structure of a colour are caused by cultural, political or purely linguistic factors.

Thirdly, as active participants in their learning process, teachers should make students realize the importance of learning idioms. Once they know the cultural and historical associations of the idioms and their etymology they will be more likely to understand and to carry out successfully all kind of activities designed for working on them.

\section{Bibliography}

Cacciari, C. and Tabossi, P. (1989). «The comprehension of Idioms», in Journal of Memory and Language, 27, 668-683.

Cacciari, C. and Levorato, M. (1989). «How children understand idioms in discourse», in Journal of child Language, 16, 387-405.

Cacciari, C. (1993.) «The Place of idioms in a literal and metaphorical World», in C. Cacciari and P. Tabossi (eds.), Idioms: Processing, Structure and Interpretation. NJ, US: Lawrence Erlbaum Associates, Inc.

Cacciari, C. and Glucksberg, S. (1995). «Understanding Idioms: Do visual images reflect figurative meanings?», in European Journal of Cognitive Psychology, 7, 3: 283-305. 
Carter, R. (1996) Vocabulary: Applied Linguistics Perspectives. London: Routledge.

Carter, R. and McCarthy, M. (1988). Vocabulary and Language Teaching. Harlow: Longman.

Collins (1995). Cobuild Dictionary of Idioms. London: HarperCollins.

Cronk and Schweigert (1992). «Novel figurative phrases and idioms: Phrase characteristics over multiple presentations», in Journal of Psycholinguistic Research, 32, 4: 455-475.

Fernando, C. and Flavell, R. (1981). On Idioms: Critical Views and Perspectives. Exeter: University of Exeter.

Fernando, C. and Flavell, R. (1992). Dictionary of Idioms and their Origins. London: Kyle Cathie.

Fernando, C (1996). Idioms and Idiomacity, Oxford: O.U.P.

Gibbs, R. (1980) «Spilling the beans on understanding and memory for idioms in conversation», in Memory and Cognition 8, 2: 149-156.

Gibbs, R., and Nayak, N. (1989). «Psycholinguistics Studies on the syntactic behaviour of idioms», in Cognitive Psychology, 21, 1: 100-138.

Gibbs, R. \& O’Brien, J. (1990). «Idioms and Mental Imagery: The Metaphorical motivation for Idiomatic Meaning. Cognition», in Second Language Research, 36, 1: 35-68.

Gibbs, R. (1992). «What do Idioms really mean?», in Journal of Memory and Language, 31: 485506.

Gibbs, R. (2002). «Mental imaginery and embodied activity», in Journal of Mental Imaginery, 26: 245-270.

Howard Bear, J. (no date) It's a colourful, colourful world: symbolism of colours. Available from http://desktoppubl.about.com/library/weekly/aa103000a.htm, accessed 10 September 2007.

Irujo, S. (1986a). «Don't put your leg in your mouth: transfer in the acquisition of idioms in a second language», in TESOL Quarterly, 20, 2: 287-304.

Irujo, S. (1986b) «A Piece of Cake: Learning and Teaching Idioms», in ELT Journal. 40, 3: 236242.

Israel, M. (2002). «Literally speaking», in Journal of Pragmatics, 34, 4: 423-432.

Kövesces, Z. and Szabó, P. (1996) «Idioms: A view from Cognitive Semantics», in Applied Linguistics , 17, 3: 326-355.

Lakoff, G. and Johnson, M. (1980). Metaphors we Live by. Chicago: Chicago University Press.

Lakoff, G. (1987). Women, Fire, and Dangerous Things: What Categories Reveal about the Mind. Chicago: Chicago University Press.

Lakoff, G. (1994). «What is metaphor?» In J. Bardnen \& K. Holyoak (eds.) Advances in Connectionist and Neural Computational Theory. Analogy, Metaphor, and Reminding. Vol. 3. Norwood, NJ: Ablex.

Moon, R. (1996). Fixed Expressions and Idioms in English: a Corpus-based Approach. Oxford: O.U.P.

Nippold, M. A. (1991). «Evaluating and enhancing idiom comprehension in language- disordered students», in Language, Speech, and Hearing Services in Schools, 22: 100-106.

Philip, G. S. (2003). Collocation and connotation: A corpus-based investigation of colour words in English and Italian. Thesis at the university of Birmingham. School of English.

Pinnavia, L. (2002). The grammaticalization of English idoms: a hypothesis for teaching purposes. Available from: http://www.ledonline.it/mpw, accessed 13 September 2007.

The Oxford English Dictionary (1993). New York: Oxford University Press. 